ISSN 1112-9867

Available online at http://www.jfas.info

\title{
STUDY OF THE EXTRACTION OF COBALT(II) FROM SULPHATE MEDIUM BY USING CAPRIC ACID DISSOLVED IN CHLOROFORM
}

\author{
A. Slimani* and D. Barkat
}

Laboratory of chemical molecular and environment, Department of Industrial Chemistry, Faculty of Science and Technology, Biskra University, 07000 Biskra, Algeria

Received: 09 September 2016 / Accepted: 12 December 2016 / Published online: 01 January 2017

\begin{abstract}
In this work we have first investigated the extraction of cobalt(II) from sulphate medium using capric acid dissolved in chloroform and then the effect of other diluents on the extraction process at $25^{\circ} \mathrm{C}$. This study aims to understand the behaviour followed by this metal or, in other words, find its stoichiometry at the end of the extraction. This deportment is strongly dependent on many parameters like $\mathrm{pH}$ of the aqueous solution, acid concentration and the nature of the solvent. Each one of these parameters will be discussed. Temperature is another parameter that will be studied in this work. At the end of this research, we have found that stoichiometry of $\mathrm{Co}(\mathrm{II})$ complex is of the type $\mathrm{CoA}_{2}(\mathrm{HR})_{2}$ (HR is an abridgment of capric acid). The equilibrium constant $\mathrm{K}_{\mathrm{ex}}$ and the thermodynamic parameters $\mathrm{H}^{\circ}, \mathrm{S}^{\circ}$, and $\mathrm{G}^{\circ}$ have been evaluated.
\end{abstract}

Keywords: Capric acid; Cobalt(II); Sulphate medium; Solvent polarity, Temperature effect.

Author Correspondence, e-mail: slimaniassia77@yahoo.fr

doi: http://dx.doi.org/10.4314/jfas. v9i1.3

\section{INTRODUCTION}

Environnemental pollution is getting more and more complex. It is, however, still attracting but marginal attention. Solvent extraction is a technique widely used for separation of one or more component from aqueous solutions and it can be one of the most effective solutions for the pollution problem, because of its sensibility and high efficiency [1-7]. Carboxylic acids occupy an important place in solvent extraction [8]. Outstanding works about carboxylic acids 
properties were established by Fletcher et al [9-12]. Capric acid was also used for the same purpose in many studies it had given a promising results. Tanaka et al [13] reported the formation of monomer $\mathrm{CoR}_{2}(\mathrm{HR})_{4}$ at lower loading of organic phase formed from capric acid dissolved in benzene and a dimer $\left(\mathrm{CoR}_{2}\right)_{2}(\mathrm{HR})_{4}$ at high loading of the organic phase. Given the importance of the solvent nature in the extraction process, its selection must be done with the utmost caution. For this consideration solvent effect has been the subject of many studies one of them is the effect of solvent in the extraction of gallium(III) with capric acid established by Yamada et al [14]. Where they found out that the degree of polymerization of extracted decanoates is even higher in the solvent with the lesser polarity than in its counterpart with higher polarity. Temperature is another important parameter that can positively or negatively influence the extraction process, sometimes temperature has no effect on this process. In this paper we investigate the solvent extraction of cobalt(II) from sulphate medium with capric acid where complex structure's formed in the organic phase was found, the effect of a number of solvents in extracting cobalt ions was studied and the effect of temperature was also discussed.

\section{EXPERIMENTAL}

\subsection{Reagents and solutions}

Capric acid (98\%, Fluka) used without further purification, organic diluents chloroform, toluene and cyclohexane were pre-quilibrated with aqueous solution which did not contain any metal. Sodium Hydroxide prepared in $(0.2 \mathrm{M})$ for the $\mathrm{pH}$ adjustment, cobalt sulphate solutions were prepared by dissolution of the respective sulphates in demineralized water (reagent grade extra pure from (Merck).

\subsection{Extraction and analytical procedure}

A mixture of equal volumes of cobalt sulphate $\left(6.8 \times 10^{-3} \mathrm{M}, 400 \mathrm{ppm}\right)$ and capric acid $(0.02 \mathrm{M}$, $0.04 \mathrm{M}$ and $0.08 \mathrm{M}$ ) dissolved in chloform, $30 \mathrm{ml}$ of each one, is mechanically shaken up in a double-walled glass vessel at $25^{\circ} \mathrm{C}$, for 30 minutes which is sufficient for reaching suitable equilibrium. The $\mathrm{pH}$ is adjusted by adding an $\mathrm{NaOH}$ solution $(0.2 \mathrm{M})$. The ionic strength of the aqueous phase was assumed to be unity $\left[\mathrm{Na}_{2} \mathrm{SO}_{4}\right]=0.33 \mathrm{M}$. The solution was allowed to settle for half an hour in order to separate the phases (the two phases are completely separated). The cobalt concentration in the aqueous solution is photometrically calculated at $510 \mathrm{~nm}$ using a Philips UV-VIS SP6-36. The organic phase concentration is the difference between the initial concentration of cobalt(II) in the aqueous solution and after the extraction. 


\section{DISCUSSION OF RESULTS}

\subsection{General treatment of the extraction equilibrium of cobalt(II) with capric acid [3]}

In the most generalized way the overall extraction of a metal ion from an aqueous layer with an acidic extractant may be written as follows:

$$
\mathrm{M}_{\mathrm{aq}}+\frac{\mathrm{n}+\mathrm{x}}{2}(\mathrm{HR})_{2, \text { org }} \rightleftarrows \frac{1}{\mathrm{j}}\left(\mathrm{MR}_{\mathrm{n}} \cdot \mathrm{xHR}\right)_{\mathrm{j}+} \mathrm{nH}_{\mathrm{aq}}^{+}
$$

The extraction constant can be written as the following expression:

$$
\mathrm{K}^{\prime}=\frac{[\mathrm{C}]_{\mathrm{org}}^{\frac{1}{\mathrm{j}}}[\mathrm{H}]_{\mathrm{aq}}^{\mathrm{n}}}{[\mathrm{M}]_{\mathrm{aq}}[(\mathrm{HR}) 2]_{\mathrm{org}}^{\frac{(\mathrm{n}+\mathrm{x})}{2}}} \cdot \frac{\gamma \mathrm{C}_{\text {org }}^{\frac{1}{j}} \gamma^{\mathrm{n}} \mathrm{H}_{\text {,aq }}}{\gamma_{\mathrm{M}, \mathrm{aq}} \gamma(\mathrm{HR})_{2, \mathrm{org}}^{\left(\frac{\mathrm{n}+\mathrm{x}}{2}\right)}}=\mathrm{KB}
$$

Where $[\mathrm{C}]=\left(\mathrm{MR}_{\mathrm{n}} \cdot \mathrm{xHR}\right)_{\mathrm{j}}$

The equation for $\mathrm{D}$ then follows eqn. (3)

$$
\mathrm{D}=\frac{[\mathrm{M}]_{\text {tot org }}}{[\mathrm{M}]_{\text {tot aq }}}
$$

$$
[C]_{\text {org }}^{\frac{1}{j}}=\left[\frac{1}{j} M\right]^{\frac{1}{j}}=[M]_{\text {org }}^{\frac{1}{j}}\left(\frac{1}{j}\right)^{\frac{1}{j}}=[M]_{\text {org }}[M]_{\text {org }}^{\frac{(1-j)}{j}}\left(\frac{1}{j}\right)^{\frac{1}{j}}
$$

Further, it follows from eq. 3 that $[\mathrm{M}]_{\text {org }}=\mathrm{D}[\mathrm{M}]_{\mathrm{aq}}$, and hence

$$
[\mathrm{C}]_{\mathrm{org}}^{\frac{1}{j}}=\mathrm{D}[\mathrm{M}]_{\mathrm{aq}}[\mathrm{M}]_{\mathrm{org}}^{\frac{(1-\mathrm{j})}{\mathrm{j}}}\left(\frac{1}{\mathrm{j}}\right)^{\frac{1}{\mathrm{j}}}
$$

Substitution of eq.4 into 2 gives for K'

$$
\mathrm{K}^{\prime}=\frac{\left\{\mathrm{D}[\mathrm{M}]_{\mathrm{org}}^{\frac{(1-\mathrm{j})}{\mathrm{j}}}\left(\frac{1}{\mathrm{j}}\right)^{\frac{1}{\mathrm{j}}}\right\}[\mathrm{H}]_{\mathrm{aq}}^{\mathrm{n}}}{\left[(\mathrm{HR})_{2}\right]^{\frac{(\mathrm{n}+\mathrm{x})}{2}}} \mathrm{~B}
$$

If we take the logarithms,

$$
\log \mathrm{D}=\log \mathrm{K}^{\prime}-\log \mathrm{B}+\left(\frac{\mathrm{j}-1}{\mathrm{j}}\right) \log [\mathrm{M}]_{\text {org }}+\left(\frac{1}{\mathrm{j}}\right) \log +\mathrm{npH}+\left(\frac{\mathrm{n}+\mathrm{x}}{2}\right) \log (\mathrm{HR})_{2}
$$




\section{Nomenclature}

M: metal ion.

HR: acidic extractant.

R: anion of extractant.

B: activity coefficient of product.

[HR]: initial extractant concentration.

$\gamma_{a . b}:$ activity coefficient for the species a in phase $b$.

$\mathrm{n}$ : number of extractant groups bound to $\mathrm{M}$ in a « salt like » manner.

$\mathrm{x}$ : number of extractant molecules bound as solvation molecules.

$\mathrm{j}$ : degree of polymerization of the extracted complex.

$\mathrm{C}$ : extracted complex.

$\mathrm{K}$ : equilibrium constant with respect toconcentrations.

$\mathrm{K}$ ': equilibrium constant with respect to activities.

\subsection{Effect of equilibrium $\mathrm{pH}$}

Profile of extracted $\mathrm{Co}(\mathrm{II})$ as a function of equilibrium $\mathrm{pH}$ at three different concentrations of capric acid: $0.02 \mathrm{M}, 0.04 \mathrm{M}$ and $0.08 \mathrm{M}$ is presented in Figure 1 . The experimental results show that the extraction percentage of cobalt increases when equilibrium $\mathrm{pH}$ values increase, it can reach $90 \%$ in the end of the extraction. For high loading of the extractant extraction takes place more quickly than low loading of the extrctant $\mathrm{pH}_{50}=7.35$ for $[\mathrm{HR}]=0.08 \mathrm{M}, \mathrm{pH}_{50}=$ 7.45 for $[\mathrm{HR}]=0.04 \mathrm{M}$ and $\mathrm{pH}_{50}=7.51$ for $[\mathrm{HR}]=0.02 \mathrm{M}$.

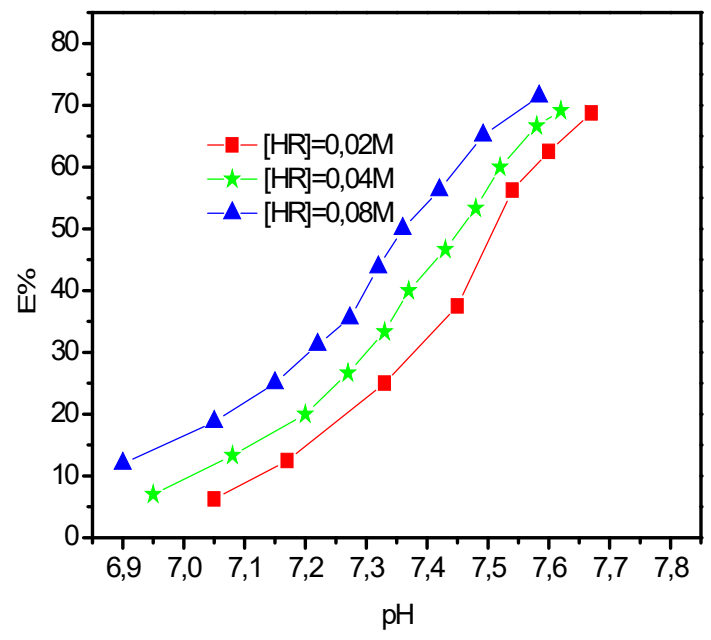

Fig.1. Percentage of extracted $\mathrm{Co}(\mathrm{II})$ with capric acid dissolved in chloroform againt the $\mathrm{pH}$. 
It was found that cobalt(II) extraction increases with the increase of $\mathrm{pH}$ of the aqueous solution (figure1). The extraction of cobalt from the sulphate solution containing about $6.78 \times 10^{3-} \mathrm{M}$ of the metal was studied by varying capric acid concentrations $(0.02 \mathrm{M}, 0.04 \mathrm{M}$ and $0.08 \mathrm{M}$ ), within the $\mathrm{pH}$ range $6.5-8$. As shown in Figure 2 the plot of $\log \mathrm{D}$ against $\mathrm{pH}$ is a linear relationship with a slope of 2 which indicates that two deprotonated capric acid have boned with one cation of cobalt(II) forming a complex during the extraction process $(n=2)$. The logarithmic equilibrium constant of cobalt(II) extracted with capric acid in chloroform at $25^{\circ} \mathrm{C}$ was calculated $\left(\log \mathrm{K}_{\mathrm{ex}}=-12.8\right)$.

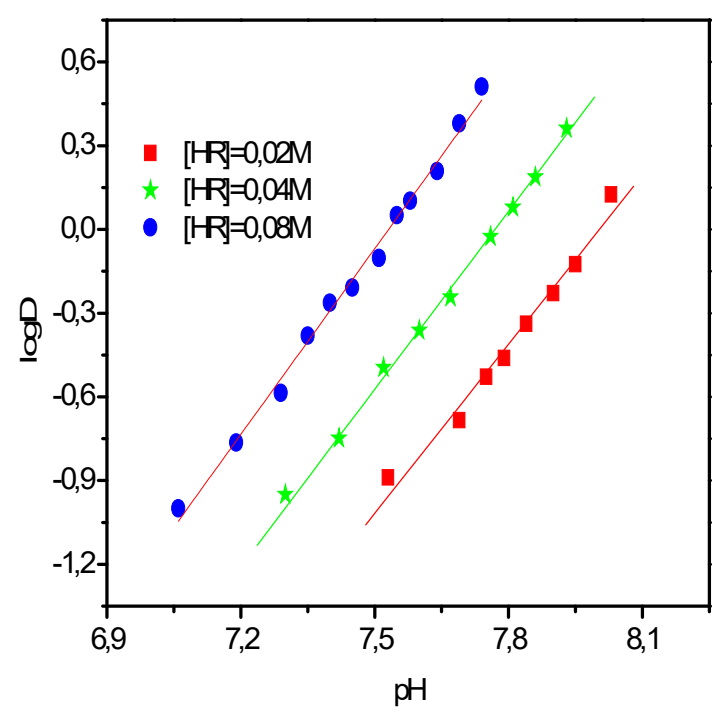

Fig.2. Effect of $\mathrm{pH}$ on the extraction of cobalt(II) from sulphate medium with capric acid dissolved in chloroform.

\subsection{Degree of polymerization}

When $\operatorname{Co}(\mathrm{II})$ is extracted into the organic phase in a form of $\mathrm{j}$-mer $\left(\mathrm{CoR}_{n} \cdot \mathrm{xHR}\right)_{\mathrm{j}}$, the corresponding equilibrium can be expressed as follows

$$
\begin{gathered}
\mathrm{jCo}^{2+}{ }_{\text {aq }}+\mathrm{j}\left(1+\frac{\mathrm{x}}{2}\right)(\mathrm{HR})_{2, \mathrm{org}} \rightleftarrows\left(\mathrm{CoR}_{2} \cdot \mathrm{xHR}\right)_{\mathrm{j}, \mathrm{org}}+2 \mathrm{jH}^{+} \\
\mathrm{K}_{\mathrm{jx}}=\frac{\left[\left(\mathrm{CoR}{ }_{2} \cdot \mathrm{xHR}\right)_{\mathrm{j}}\right]_{\mathrm{org}}[\mathrm{H}]_{\mathrm{aq}}^{2 \mathrm{j}}}{\left[\mathrm{Co}^{2+}\right]_{\mathrm{aq}}^{\mathrm{j}}\left[(\mathrm{HR})_{2}\right]_{\mathrm{org}}^{\frac{\mathrm{j}(2+\mathrm{x})}{2}}}
\end{gathered}
$$

We will use the method applied by Tanaka in his works[15-18] 


$$
\mathrm{C}_{\mathrm{Co}, \text { org }}=\sum_{\mathrm{j}}^{\mathrm{J}} \sum_{\mathrm{x}=0}^{\mathrm{x}} J\left[\left(\mathrm{CoR}_{2} \cdot \mathrm{xHR}\right)_{\mathrm{j}}\right]_{\mathrm{org}}=\sum_{\mathrm{j}=1}^{\mathrm{J}} \sum_{\mathrm{x}=0}^{\mathrm{x}} \mathrm{j} \mathrm{K}_{\mathrm{jx}}\left(\mathrm{C}_{\mathrm{Co}, \mathrm{aq}}\right)^{\mathrm{j}}\left[(\mathrm{HR})_{2}\right]_{\mathrm{org}}^{\frac{\mathrm{j}(2+\mathrm{x})}{2}}[\mathrm{H}]_{\mathrm{aq}}^{-2 \mathrm{j}}\left(\alpha_{(\mathrm{Co})}\right)^{-\mathrm{j}}
$$

Where

$$
\mathrm{D}=\sum_{\mathrm{j}=1}^{\mathrm{J}} \sum_{\mathrm{x}=0}^{\mathrm{x}} \mathrm{j} \mathrm{K}_{\mathrm{jx}}\left(\mathrm{C}_{\mathrm{Co}, \mathrm{aq}}\right)^{\mathrm{j}-1}\left[(\mathrm{HR})_{2}\right]_{\mathrm{org}}^{\frac{\mathrm{j}(2+\mathrm{x})}{2}}[\mathrm{H}]_{\mathrm{aq}}^{-2 \mathrm{j}}\left(\alpha_{(\mathrm{Co})}\right)^{-\mathrm{j}}
$$

When only $\left(\mathrm{CoR}_{2} \mathrm{xHR}\right)_{\mathrm{j}}$ is responsible for the extraction, summation in equation (8) can be dropped and $\log \mathrm{C}_{\mathrm{M} \text {,org }}$ is equated as follows:

$\log \mathrm{C}_{\mathrm{Co}, \mathrm{org}}=\mathrm{j}\left(\log \mathrm{C}_{\mathrm{Co}, \mathrm{aq}}+2 \mathrm{pH}-\log \alpha_{(\mathrm{N})}\right)+\log \mathrm{j}+\log \mathrm{K}_{\mathrm{jx}}+\mathrm{j}\left(1+\frac{\mathrm{x}}{2}\right) \log \left[(\mathrm{HR})_{2}\right]_{\text {org }}$

Thus the degree of polymerization of the caprate can be found from the slope of the plot of $\log \mathrm{C}_{\mathrm{Co}, \text { org }}$ against $\log \mathrm{C}_{\mathrm{Co}, \mathrm{aq}}+2 \mathrm{pH}-\log \alpha_{(\mathrm{Co})}$ at constant $\left[(\mathrm{HR})_{2}\right]$. Under our experimental condition the hydrolysis of cobalt(II) in the aqueous phase is neglected, i.e $\alpha_{(\mathrm{Co})}=1$. j being the degree of polymerization of the cobalt-Capric acid compound; were calculated from the $\log \mathrm{C}_{\mathrm{Co}, \text { org }}$ graph versus $\log \mathrm{C}_{\mathrm{Co}, \mathrm{w}}-2 \log \left[\mathrm{H}^{+}\right]$as shown in figure 3 , We got a straight lines with a slope of the unity for each one this means $j=1$. Therefore, the extracted species are monomers of the $\left(\mathrm{CoR}_{2} \mathrm{xHR}\right)$ type. We have to say that extraction with fatty acids like capric acid proceeds by cation exchangers where proton of the acid is exchanged by metal ion.

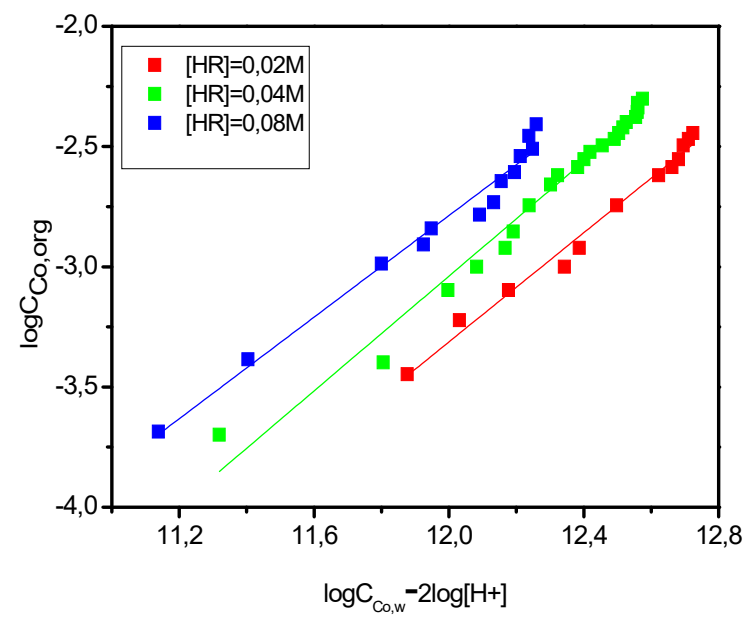

Fig.3. Determination of the degree of polymerisation of cobalt(II) caprylates. 


\subsection{Effect of extractant concentration}

The $\mathrm{x}$ number of capric acid involved in the monomeric species was determined from the $\log \mathrm{D}$ slope versus $\log \left[(\mathrm{HR})_{2}\right]$ (according to equation5). Drawing of $\log \mathrm{D}$ versus $\log (\mathrm{HR})_{2}$ produces straight lines with slopes of 2 (figure 4) which lead to conclude that x takes 2 as a value. Three unknown are determined $(n=2, j=1$ and $x=2)$ which allow us to know the extracted complex stoïchiometry which is $\mathrm{CoR}_{2}(\mathrm{HR})_{2}$. The stoïchiometry of the extracted species is in agreement with that found in earlier works [19-21] and is the same found in the extraction of cobalt(II) with hexanoic,octanoic and capric acid in heptanes determined by Kopach et coll [22]. However Tanaka et coll [13] found that the two forms existed when working with high concentrations of the extractant suggesting that formed species depend on experimental conditions.

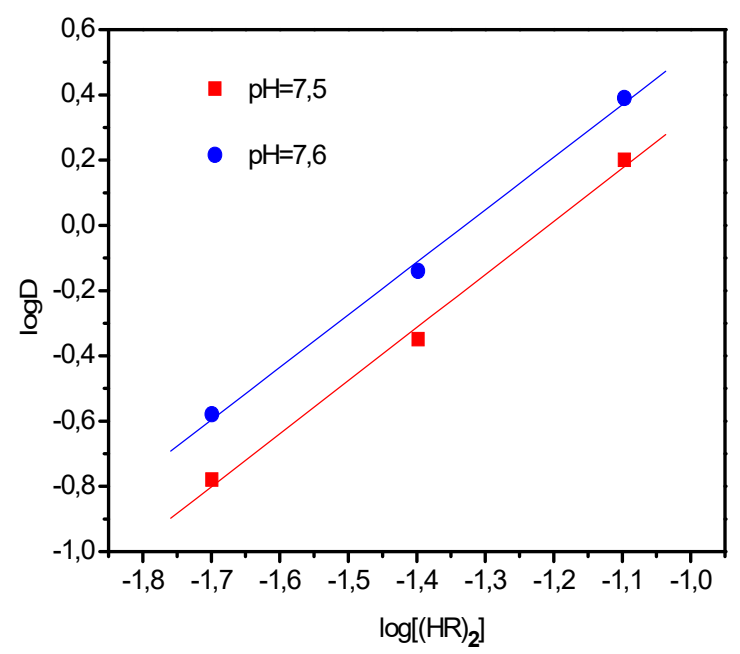

Fig.4. Effect of the extractant concentration on the extraction of cobalt(II) with capric acid at $25^{\circ} \mathrm{C}$

We can then re-formulate equilibrium 1 as follows

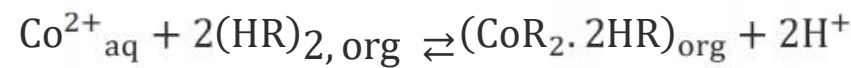

The UV-visible spectrum of deep pink complex $\mathrm{Co}(\mathrm{II})$ that appears in figure 5 is characterized by a single broad shoulder with a maximum at approximately $500 \mathrm{~nm}$. This is related to the absorptions expected for an octahedral geometry of cobalt(II) complex [23]. As figure 6 shows the coordination sphere of $\mathrm{Co}(\mathrm{II})$ is occupied by two molecules of capric acid that are coordinated to the central metal while the remaining two sites have a high probability of being occupied by two water or solvent molecules. 


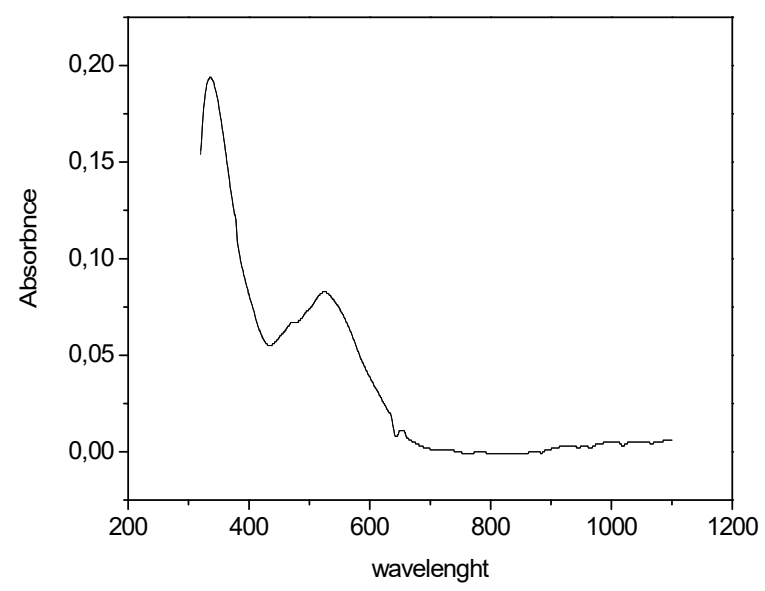

Fig.5. Visible spectrum of the organic phase during the extraction of $\mathrm{Co}(\mathrm{II})$ with $0.04 \mathrm{M}$ of capric acid dissolved in chloroform

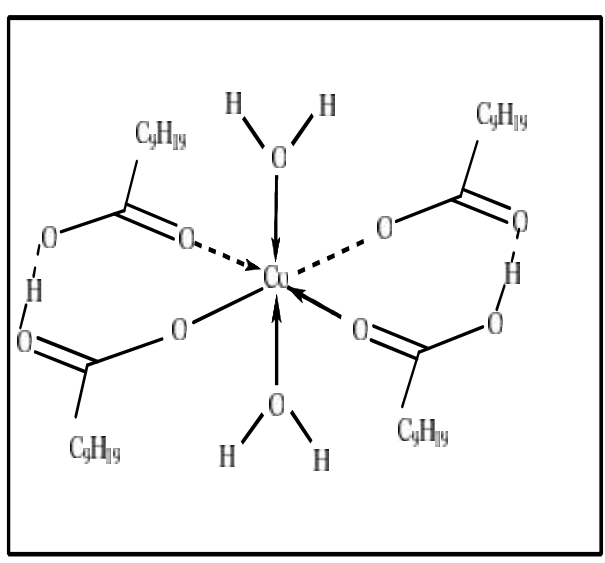

Fig.6. Possible structure of the cobalt(II) complex extracted with capric acid dissolved in chloroform.

\subsection{Effect of organic solvent}

Three different diluents were tested for the extraction of $\mathrm{Co}(\mathrm{II})$ from sulphate solutions using constant capric concentration $(0.04 \mathrm{M})$. We know that efficiency of extraction is affected by chosen solvents [24-25] extraction of cobalt(II) with capric acid was elaborated by using chloroform, cyclohexane and toluene. To clarify the effect of diluent the $\mathrm{D}_{\mathrm{Co}}$ values were measured for selected diluents under the same conditions. The data obtained is plotted against $\mathrm{pH}$ (figure7) where we got the higher Dco when using chloroform and the lower Dco when using toluene, the best extraction order was: cyclohexane > chloroforme > toluene. Adjel studied the effect of diluents on the extraction of cobalt, she revealed that the extraction of cobalt(II) by capric acid decreased in the order: chloroform > dichloromethane > MIBK [26]. 


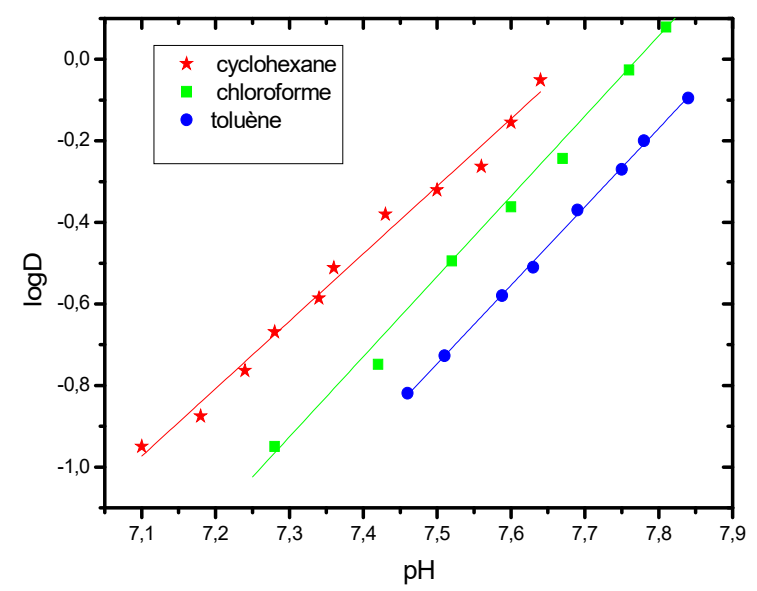

Fig.7. Effect of solvents on the extraction of cobalt(II) from sulphate medium with $0.04 \mathrm{M}$ of capric acid dissolved in chloroform.

\subsection{Effect of temperature}

Temperature impact on the extraction of of Co(II), using 0.04M of capric acid dissolved into chloroform was examined within a $10^{\circ} \mathrm{C}-50^{\circ} \mathrm{C}$ range at fixed aqueous and fixed extractant concentrations. $\log \mathrm{D}_{\mathrm{Co}}$ profile as oppose to $\mathrm{pH}$ is displayed in figure 8 . It is obvious that the rise in temperature entails a significant increase in the distribution coefficient and therefore extracted metal ratio. At higher temperatures viscosity of the organic phase is lower which guaranty better contact between organic and aqueous phase during mixing. Vander Zeeuw [27] had also found the positive effect of the temperature in the extraction of iron $\mathrm{Fe}(\mathrm{III})$ with versatic acid where increase of temperature from $20^{\circ} \mathrm{C} \mathrm{o} 80^{\circ} \mathrm{C}$ causes an appreciable increase of distribution coefficient.

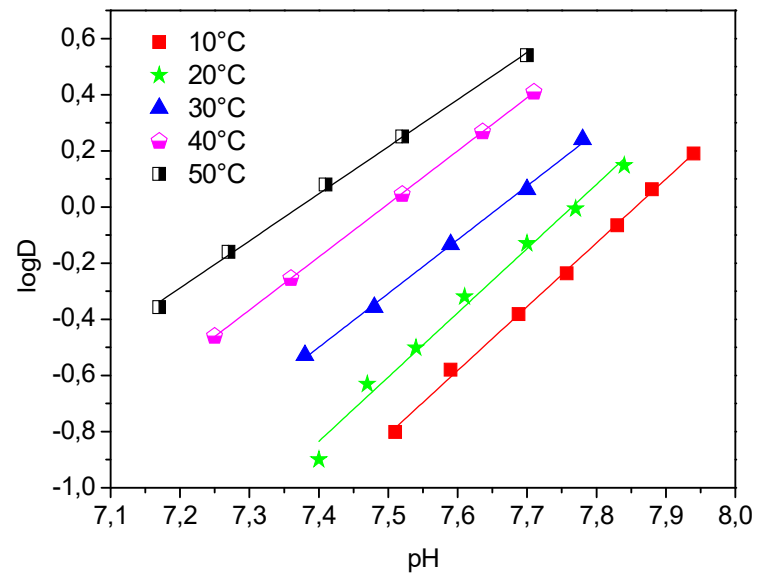

Fig.8. Effect of temperature on extracted cobalt(II) from sulphate medium with capric acid 
The obtained values of $\log \mathrm{K}_{\mathrm{ex}}$ at different temperatures are summarized in table 1 , the relation between $\log \mathrm{K}_{\mathrm{ex}}$ and the thermodynamic parameters can be expressed as

$\log \mathrm{K}_{\mathrm{ex}}=\frac{-\Delta \mathrm{H}^{\circ}}{2.303 \mathrm{RT}}+\frac{-\Delta \mathrm{S}^{\circ}}{2.303 \mathrm{R}}$

plotting $\log \mathrm{K}_{\mathrm{ex}}$ against $1 / \mathrm{T}$ gives a straight line of slope of $\frac{-\Delta \mathrm{H}^{\circ}}{2.303 \mathrm{R}}$ and a y-intercept of

$\frac{-\Delta S^{\circ}}{2.303 R}$ (figure 9), free energy can be then calculated from one of the followed equations

$$
\Delta \mathrm{G}=-\mathrm{RT} \ln \mathrm{K}_{\mathrm{ex}}(13) ; \Delta \mathrm{G}=\Delta \mathrm{H}-\mathrm{T} \Delta \mathrm{S}
$$

Table 1. Values of the extraction constants of cobalt(II) at different temperatures

\begin{tabular}{|c|c|c|c|c|c|}
\hline $\mathrm{T}\left({ }^{\circ} \mathrm{K}\right)$ & 283 & 293 & 303 & 313 & 323 \\
\hline $\log _{\mathrm{ex}}$ & -13.01 & -12.90 & -12.74 & -12.40 & -12.01 \\
\hline
\end{tabular}

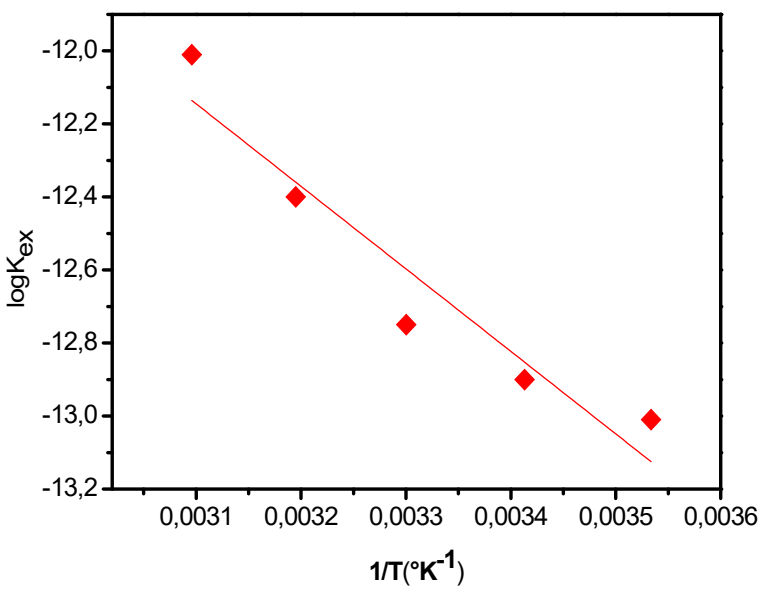

Fig.9. Relationship between distribution constant of extracted cobalt(II) and temperature

Table 2. Thermodynamic parameters for cobalt(II) extraction

\begin{tabular}{|c|c|c|}
\hline $\mathrm{H}^{\circ}\left(\mathrm{kJ} \mathrm{mol}^{-1}\right)$ & $\mathrm{G}^{\circ}\left(\mathrm{kJmol}^{-1}\right)$ & $\mathrm{S}^{\circ}\left(\mathrm{J} \mathrm{mol}^{-1} \mathrm{~K}^{-1}\right)$ \\
\hline 43.25 & 13.45 & 98.33 \\
\hline
\end{tabular}

Where, $\Delta H, \Delta \mathrm{G}$ and $\Delta \mathrm{S}$ are the enthalpy change, the free energy change, and entropy change, respectively, $R$ is the universal gas constant $\left(8.314 \mathrm{Jmole}^{-1} \mathrm{~K}^{-1}\right), \mathrm{T}$ is the absolute temperature and $\mathrm{K}_{\mathrm{ex}}$ is the extraction constant. These thermodynamic parameters of the extraction of $\mathrm{Co}$ (II) were calculated and given in Table 2 . The data obtained shows that the enthalpy variation, $\Delta \mathrm{H}$, have a positive value indicating the endothermic character of the extraction process which explain the improve of extraction when increasing 
temperature. The positive value of the free energy change ( $G)$ means that the extraction of cobalt(II) in the investigated system is not a spontaneous reaction. The positive sign of $\Delta \mathrm{S}$ value reveals the disordering nature of the extracted metal species in the investigated system.

\section{CONCLUSION}

Stoichiometry of cobalt(II) complex extracted with capric acid dissolved in chloroform is from the type $\mathrm{CoR}_{2}(\mathrm{HR})_{2}$. This result was found by the method of slopes, the formed complex has an octahedral structure where the coordination sphere of Co (II) is occupied by two molecules of capric acid that are coordinated to the central metal. According to the nature of the solvent, the extraction of $\mathrm{Co}(\mathrm{II})$ by capric acid decreased in the order: Cyclohexane>chloroform >toluene. Rising temperature in the range from $10^{\circ} \mathrm{C}$ to $50^{\circ} \mathrm{C}$ had a good impact on the extraction rate of $\mathrm{Co}(\mathrm{II})$ ions.

\section{REFERENCES}

[1] Ashbrook AW. Extraction of metals from ammonium sulphate solution using a carboxylic acid-I. Cobalt. J. Inorg. Nucl. Chem, 1972, 34, 1721-1737.

[2] Fletcher AW, and Flett DS. Equilibrium studies on the solvent extraction of some transition metals with naphtenic acid. J.Appl. Chem, 1964, 14, 250-257.

[3] Vander Zeeuw AJ. Metals extraction with carboxylic acids. I. Composition of complexes with nickel, cobalt(II) and iron(III). Hydrometallurgy, 1979, 4, 21-27.

[4] Michael J. Jaycock. Solvent extraction and adsorptive bubble separation of metal ions from aqueous solution-I- Solvent extraction using carboxylic acids and their salts as extractants. J. Inorg. Nucl. Chem, 1972, 36, 887-898.

[5] Marcus Y, Kertes A S. Ion exchange and solvent extraction of metal complexes. WileyInterscience, 1969, p. 1037.

[6] Preston JS. Solvent extraction of metals by carboxylic acids. Hydrometallurgy, 1985, 3, 171-188.

[7] Beneitz P, Espejo J, SJ. And Ortega J. Study of the main extracted species of cobalt(II) ion with dodecylthioglycolic acid as extractor. Can. J. Chem, 2004, 64, 15-18.

[8] Rice NM. Recent developments and potential uses for carboxylic acid extractants. Hydromettallurgy, 1978, 3, 111-133.

[9] Fletcher AW, and Flett DS.US patent 3055754, 1962. 
[10] Fletcher AW, and Hester KD. Trans.AIME, 1964, 229-282.

[11] Fletcher AW, Flett DS, and Wilson JC. Solvent extraction of ferric iron by a carboxylic acid. Trans. Inst. Miner. Metal, 1964, 73, 765.

[12] Fletcher AW, and Flett DS. In Proc.Int.Conf. on the Chemistry of Solvent Extraction. Harwell, London: Macmillan, 1965, 359.

[13] Tanaka M, Niinomi T. Extraction of cobalt(II) with capric acid dissolved in benzene. J. Inorg. Nucl. Chem, 1965, 27:431.

[14] Yamada H, Imai S, Takeuchi E. Solvent effect on the extraction of gallium(III) with decanoic acid. Bull. Chem., Soc Jpn, 1983, 56, 1401-1406.

[15] Tanaka M, Nakasuka N, and Sasane S (née Goto). Extrction of nickel with capric acid. J. Inorg. Nucl. Chem, 1968, 31, 2591-2597.

[16] Noriyuki Nakasuka, Masahiko Nakai and Motoharu Tanaka. Extrction of lead(II) with capric acid. J. Inorg. Nucl. Chem, 1970, 32, 3667-3672.

[17] Noriyuki Nakasuka, Katsumi Hirose and Motoharu Tanaka. Extrction of uranium(VI) with capric acid. J. Inorg. Nucl. Chem, 1972, 35, 265-269.

[18] Nobutake Kodama, Hiromici Yamada and Motoharu Tanaka. Extrction of berkelium with capric acid. J. Inorg. Nucl. Chem, 1975, 38, 2063-2065.

[19] Tsakiridis PE, and Agatzini SL,Miner. Eng, 2004, 17, 535-543.

[20] Abdel-Fattah AA. Thermodynamic studies on cobalt(II) extraction by 2-heptyl-2methylnonanoic acid in benzene from chloride solutions. Russ in Radiokhim, 2010, 52, 224228.

[21] Beneitz P, Espejo J, SJ. And Ortega J. Extraction of zinc, cobalt and iron with s-terdodecylthioglycolic acid. J. Inorg. Nucl. Chem, 1981, 43, 2517-2523.

[22] Kopach S, Shantulya Ya, Kalem'kevich Ya and Pardelaya T. Zh. Neorg.Khim, 1981,26, 1625 .

[23] Krishna. Ch, Mohapatra C, Kailash C Dush. 4-5 and 6-coordinate complexes of copper(II) with substituted imidazole. J. Inorg. Nucl. Chem, 1977, 39, 1253.

[24] Hiromichi Yamada, Hisao Hayashi, Yukio Fujii, and Masateru Mizuta. Solvent effects on extraction of aluminium(III), Gallium(III), and indium(III) with decanoic acid. Chem.Soc. Jpn, 1986, 59,789-794.

[25] Van de Voorde I, Pinoy L, Coutijn E, Verport F. Influence of acette ions and the role of the diluents on the extraction of copper(II), nickel(II), cobalt(II), magnesium(II), and iron(II, III) with different types of extractants. Hydrometallurgy, 2005, 78. 
[26] Adjel, F. Thèse de Doctorat, Université de Biskra, 2011.

[27] Vander Zeeuw AJ. Metals extraction with carboxylic acids. II. Effect of temperature on the extraction of $\mathrm{Cu}, \mathrm{Ni}, \mathrm{Co}(\mathrm{II}), \mathrm{Zn}, \mathrm{Fe}(\mathrm{III})$ and $\mathrm{Co}(\mathrm{III})$. Hydrometallurgy, 1979, 4, 39-50.

\section{How to cite this article:}

Slimani A, and Barkat D. Study of the extraction of cobalt(ii) from sulphate medium by using capric acid dissolved in chloroform. J. Fundam. Appl. Sci., 2017, 9(1), 23-35. 